\title{
Subhepatic appendicitis: A diagnostic conundrum
}

\author{
Biji Thomas George ${ }^{\star}$, Youmna Ayman², Hadi Zafar², Godfred Menezes³
}

'Department of Surgery, RAK Medical and Health Sciences University, Ras Al-Khaimah, United Arab Emirates, ${ }^{2}$ RAK Medical and Health Sciences University, Ras Al-Khaimah, United Arab Emirates, ${ }^{3}$ Department of Microbiology, RAK Medical and Health Sciences University, Ras Al-Khaimah, United Arab Emirates

\begin{abstract}
One of the most common presentations of acute abdominal pain in the emergency setting is appendicitis. Although it can occur in both genders, when it comes to females with appendicitis, reaching a definite diagnosis can be challenging as it can mimic other diseases such as ovarian cysts/torsions, pelvic inflammatory diseases, endometriosis, and urinary tract infection or physiological reasons like menstrual pain which are exclusive to females and can occur as frequently as appendicitis. Therefore, it is crucial to make an accurate diagnosis as early as possible with the right diagnostic tools to reduce morbidity and mortality in females of child-bearing age. This is a summarized case report of an adolescent female who experienced two atypical attacks of appendicitis 1 year apart. Since the patient had mainly right upper flank pain associated with nausea, vomiting, and fever with a largely non-tender abdomen, various diagnoses such as chronic cholecystitis, biliary colic, peptic ulcer, gastroenteritis, mesenteric lymphadenitis, renal colic, mittelschmerz, and torsion of ovarian cyst were considered and treated for. The patient had no relief and underwent numerous investigative procedures in the 2 years she suffered from her illness. The final diagnosis was only obtained when exploratory laparoscopy was performed. This article aims to remind clinicians to have a high index of suspicion for acute appendicitis in all atypical presentations of acute appendicitis. The latest WSES Jerusalem guidelines for the workup for patients at risk of acute appendicitis should be meticulously followed.
\end{abstract}

Keywords: Abdominal pain; adult appendicitis score; Alvarado score; appendicitis inflammatory response score; appendix; scoring; subhepatic appendicitis

\section{INTRODUCTION}

Appendicitis can happen due to a variety of reasons, such as infection, obstruction of the lumen by a fecalith, enlargement of the lymph nodes in the mucosa of the appendix, or obstruction from surrounding structures, all leading to the same pathophysiology of stasis of secretions which, in turn, leads to inflammation (1).

Appendectomy is the mainstay curative procedure performed worldwide in men and women in all age groups. Typically, patients with uncomplicated acute appendicitis present with fever, vomiting, right lower abdominal pain, as well as other signs, symptoms, and laboratory investigations that fulfill the Alvarado score (a clinical scoring system helpful in the diagnosis of appendicitis) (2). In an atypical case of appendicitis, symptoms will not be similar to a classical presentation of appendicitis, which makes these patients tricky to diagnose.

In young adults and adolescents with symptoms and laboratory findings consistent with that of a typical case of

*Corresponding author: Biji Thomas George, Department of Surgery, RAK Medical and Health Sciences University, Ras Al-Khaimah, United Arab

Emirates. Phone: +97-1501163495. E-mail: biji@rakmhsu.ac.ae

Submitted: 20 February 2021/Accepted: 07 May 2021

DOI: https://doi.org/10.17532/jhsci.2021.1265 appendicitis, one of the Alvarado scores, adult appendicitis score (AAS), or appendicitis inflammatory response score (AIR) are calculated to exclude or include the possibility of having the condition. If the scores calculated lean toward a possible case of appendicitis, the patient should undergo point-of-focus ultrasound (POCUS) as the first-line investigation. If ultrasound findings are inconclusive, a contrast-enhanced low-dose computed tomography (CT) scan is to be ordered. The last resort of investigation given that both POCUS and CT are inconclusive of a final diagnosis is exploratory laparoscopy (3). Misdiagnosis is common and can delay definitive diagnosis in such patients, so it is important to achieve a timely diagnosis and management as it is crucial for the patient's survival as appendicitis complications such as perforation, peritonitis, and sepsis may occur rapidly leading to an increased risk in mortality (4). Diagnostic accuracy of atypical appendicitis needs to be improved worldwide to guide physicians into making the right decision at the right time. Efforts should be made in distinguishing and recognizing typical from atypical presentations of appendicitis.

\section{CASE REPORT}

A 17-year-old female presented to the emergency room with complaints of upper abdominal pain. The pain started 
following a heavy meal that evening, it was described as stabbing pain, radiating to the flanks, lower chest, and upper back. Associated symptoms included fever, nausea, and vomiting. The pain was constant, it was not related to vomiting, defecation, or urination. Exacerbating factors included lying in a supine position. The severity was rated $10 / 10$ by the patient. The patient vomited twice, once following the meal that evening, the vomit was about a bowl full, consisting of food matter, it was light brown, containing no blood, and no unusual smell. The second occurrence was a few hours later in the ER, it consisted of gastric fluids and was about a cup full. As for the fever, it was constant, and started along with the pain, and decreased with the administration of antipyretic medications. Her menstrual cycles were normal.

The patient denied the presence of any dark-colored urine, burning sensation during micturition, diarrhea, constipation, blood in stools, recent viral throat infections, as well as irregular menstrual cycles.

The patient recalls that she suffered from a similar incident in the past about a year before the present admission. Back then, she had fever, vomiting, and pain of the same character with normal menstrual cycles. She was managed by multiple doses of intravenous (IV) analgesics which settled the pain and discharged later that day.

There was no other relevant medical, social, and family history. Laboratory parameters on admission were as follows (Tables 1-5).

Urinalysis results showed clear, yellow urine, $\mathrm{pH} 5.5$, proteins, glucose, blood, bilirubin, urobilinogen, nitrites, casts, epithelial cells, and red blood cells (RBCs) were all absent. Ketones ++ and 8-10 pus cells were found.

Ultrasound whole abdomen: There was a large right ovarian cyst measuring about $7.3 \mathrm{~cm} \times 2.6 \mathrm{~cm}$ (Figure $1 \mathrm{a}$ and $\mathrm{b}$ ). The left ovary appeared normal. No other remarkable findings were present. Ultrasound Doppler pelvis revealed a large cystic lesion measuring $72 \mathrm{~mm} \times 62 \mathrm{~mm} \times 51 \mathrm{~mm}$ with a volume of $121 \mathrm{ml}$ in the right adnexa with a few intracystic thin septations. Good vascularity of the walls of the cystic lesion was noted hence ruling out torsion. A few mesenteric lymph nodes were noticed in the right iliac fossa. Cortical echogenicity of the right kidney was increased. Minimal right iliac fossa collection was present; volume $8.4 \mathrm{ml}$ along with minimal ascites in the left iliac fossa and pelvis. Bilateral minimal pleural effusion $6.3 \mathrm{ml}$ right side and $2.1 \mathrm{ml}$ in the left was also noted.

Magnetic resonance imaging (MRI) abdomen without contrast showed right ovarian cyst. No other remarkable findings were noted.

CT scan of the whole abdomen with oral contrast (Figure 2) showed hepatomegaly. Extensive thickening of walls and haustral folds of the ascending colon, proximal half of transverse colon and cecum, as well as terminal ileum with extensive pericolonic and peri-ileal fat stranding along with the thickening of the Gerota's fascia was found. On the right - extensive colitis with pericolonic inflammation was also noticed. Appendix was thickened and edematous with lack of intraluminal air. A few enlarged mesenteric lymph nodes were presented with the largest measuring $13 \mathrm{~mm} \times$ $10 \mathrm{~mm}$. Minimal subcapsular collection in relation to the
TABLE 1. Vital parameters

\begin{tabular}{lc}
\hline Temperature $\left({ }^{\circ} \mathrm{C}\right)$ & 37.8 \\
Pulse rate (beats/minute) & 80 \\
Blood pressure $(\mathrm{mmHg})$ & $100 / 60$ \\
Respiratory rate (breaths/minute) & 20 \\
$\mathrm{SpO} 2(\%)$ & 99 \\
Weight $(\mathrm{Kg})$ & 48 \\
\hline
\end{tabular}

TABLE 2. Immunoassay

\begin{tabular}{lc}
\hline Presepsin $(\mathrm{mg} / \mathrm{L})$ & 104 \\
Procalcitonin $(\mathrm{ng} / \mathrm{mL})$ & 0.218 \\
\hline
\end{tabular}

TABLE 3. Liver function tests

\begin{tabular}{lc}
\hline Bilirubin total $(\mathrm{mg} / \mathrm{dL})$ & 0.22 \\
Bilirubin direct $(\mathrm{mg} / \mathrm{dL})$ & 0.09 \\
Alanine transaminase $(\mathrm{U} / \mathrm{L})$ & 12.31 \\
Aspartate aminotransferase $(\mathrm{U} / \mathrm{L})$ & 16.20 \\
Alkaline phosphatase $(\mathrm{U} / \mathrm{L})$ & 75.45 \\
Gamma-glutamyl transpeptidase $(\mathrm{U} / \mathrm{L})$ & 9.94 \\
Protein total $(\mathrm{g} / \mathrm{dL})$ & 6.99 \\
Albumin $(\mathrm{g} / \mathrm{dL})$ & 4.97 \\
\hline
\end{tabular}

TABLE 4. Complete blood count

\begin{tabular}{lc}
\hline Hemoglobin (g/dL) & 10.6 \\
Hematocrit (\%) & 32.5 \\
RBC count (million/mm³) & 3.9 \\
Mean corpuscular volume (fL) & 83.1 \\
Mean corpuscular hemoglobin (pg) & 27.1 \\
Mean corpuscular hemoglobin concentration (g/dl) & 32.6 \\
Red cell distribution width (\%) & 13.0 \\
Total WBC count (10^9/L) & 13.2 \\
Neutrophils (\%) & 86.5 \\
Lymphocytes (\%) & 8.7 \\
Monocytes (\%) & 4.6 \\
Eosinophils (\%) & 0.0 \\
Basophils (\%) & 0.2 \\
Platelet count (10^9/L) & 210 \\
CRP (mg/L) & 270.78 \\
\hline CRP: C-reactive protein; WBC: White blood cell; RBC: Red blood cell
\end{tabular}

TABLE 5. Renal function profile

\begin{tabular}{lc}
\hline Urea $(\mathrm{mmol} / \mathrm{L})$ & 3.27 \\
Albumin $(\mathrm{g} / \mathrm{dL})$ & 4.97 \\
Calcium $(\mathrm{mg} / \mathrm{dL})$ & 9.45 \\
Phosphorus (mg/dL) & 3.74 \\
Sodium (mmol/L) & 143 \\
Potassium (mmol/L) & 3.60 \\
Chloride (mmol/L) & 107 \\
Bicarbonates (mmol/L) & 19.14 \\
\hline
\end{tabular}

Lower than normal $\quad$, Higher than normal

right kidney was noted. Minimal pericholecystic collection was present. A hypodense lesion measuring $66 \mathrm{~mm} \times$ $50 \mathrm{~mm}$ in the right adnexa inseparable from the right ovary was seen, suggestive of an ovarian cyst.

\section{Diagnostic assessment}

The patient had symptoms of continuous fever $\left(37.8^{\circ} \mathrm{C}\right)$, nausea, non-bloody non-bilious vomiting along with upper 


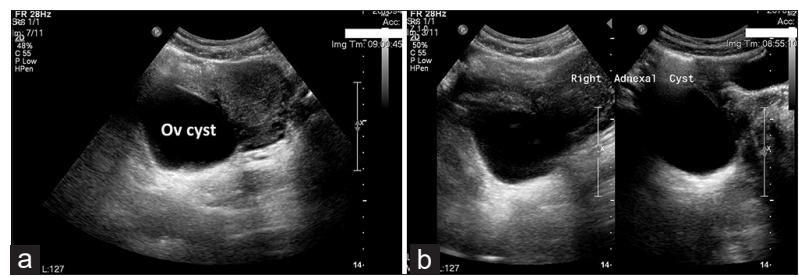

FIGURE 1. (a) ultrasound scan showing large right ovarian cyst, (b) ultrasound scan showing large cystic lesion in the right adnexa with few intracystic septations

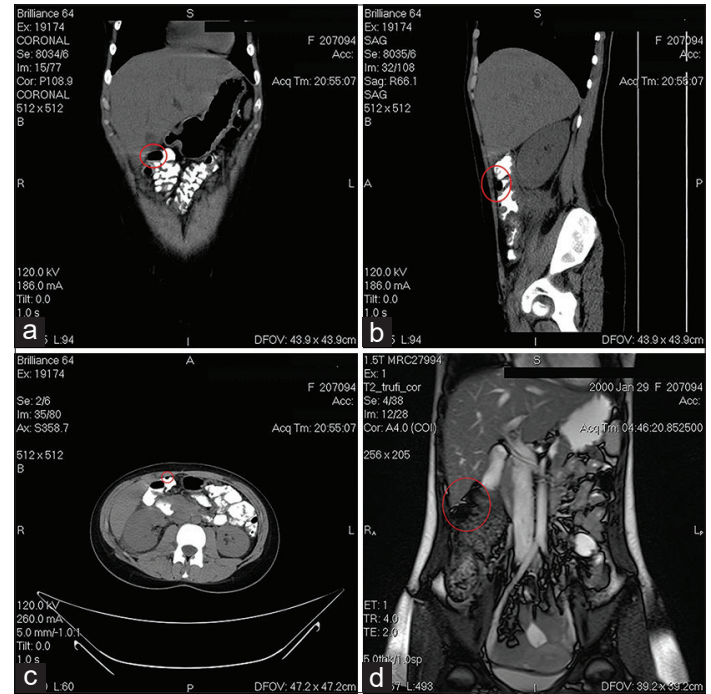

FIGURE 2. (a) Appendicular abscess at subhepatic space (red circle) seen on coronal computed tomography, (b) Appendicular abscess at subhepatic space on sagittal view, (c) Gangrenous appendix shown in transverse computed tomography, (d) Paracolic abscess shown in coronal MRI.

abdominal pain radiating to the flanks (Table 1). She reported normal menstruation at presentation. On questioning, there was no positive history of diarrhea, constipation, or any changes in stool or dysuria.

Positive laboratory findings include total white blood cell $(\mathrm{WBC}): 13.2 \times 10^{\wedge} 9 / \mathrm{L}, \mathrm{C}$-reactive protein $(\mathrm{CRP})$ $270.78 \mathrm{mg} / \mathrm{L}$, and neutrophils $86.5 \%$, indicating the presence of an acute infection in the body (Tables 2-5).

Positive radiological findings include the presence of a few mesenteric lymph nodes, mild hepatomegaly, colitis along with inflammation and thickening of ascending colon walls, and proximal half of transverse colon and terminal ileum. It also revealed the presence of a thick appendix with lack of intraluminal air.

On arrival to the emergency room, the patient was asked about menstrual history to rule out mittelschmerz. She underwent an ultrasound scan which revealed a large right ovarian cyst. However, since the cyst had good vascularity in the walls, ovarian torsion was ruled out. The location of the pain, located at the upper abdomen and flanks also made the possibility of ovarian pathology being the source of pain remote (5).

Peptic ulcer was also suspected due to the site of pain being in the upper abdominal area, radiating to the back, which could indicate a possible perforation. Recent history of ibuprofen intake was present which could have precipitated acid peptic disease. This was excluded clinically as the pain not related to food intake (6).
Further, investigations were done to exclude any urinary pathology. Renal function tests as well as a urinalysis were carried out where urea, albumin, calcium, and bicarbonate levels were normal (Table 5). Urinalysis revealed that 8-10 pus cells were present and ketones ++. It was otherwise clear as there were no glucose, proteins, RBCs, blood products, casts, and nitrites. CT scan of the abdomen showed minimal subcapsular collection to the right kidney. However, both kidneys were normal in size with no obvious stones along the tract. The patient also denied burning sensation on micturition, dark-colored urine, and any recent sexual activity that could predispose to a urinary tract infection (UTI) (5).

Abdominal pain, fever, and vomiting are all present with high levels of CRP (Table 4) indicating an acute inflammation, a case of gastroenteritis could be suspected. Yet, the patient had no complaints of watery or bloody diarrhea, thus excluding the possibility of gastroenteritis.

On CT, a few enlarged mesenteric lymph nodes were detected in the right iliac fossa.

Symptoms such as fever, vomiting, nausea, as well as relevant laboratory findings of leukocytosis and a high CRP count could indicate the presence of an infection.

Other than the presence of enlarged mesenteric lymph nodes as a clue, upon palpation, the physician noted the presence of a mass felt on deep palpation of the right lower quadrant of the abdomen, being unsure of what it could be, the decision of going for an exploratory laparoscopic procedure was made.

During laparoscopy, a long retrocecal gangrenous appendix causing inflammation and thickening of the ascending colon on its way to the liver base, along with an appendiceal abscess (mass) and perirenal collection of pus. The location of the tip of the appendix explained the atypical symptoms that the patient presented with.

\section{Therapeutic intervention}

A year before this incident, the patient suffered from sudden upper abdominal pain as well as flank pain which woke her up from her sleep, severe enough to hinder her ability to move on the way to the hospital the patient vomited once, the vomit consisted of non-bilious gastric contents. In the emergency room, the patient was given paracetamol and acetaminophen to ease the pain. Investigations such as a complete blood count, urinalysis, ultrasound, and an MRI were performed, which were clear and not suggestive of any obvious problem, except for a simple ovarian cyst. She was given IV paracetamol until the pain subsided and was sent home. She visited the gynecologist every month for 3 months to check the progression of the ovarian cyst which decreased in size overtime and caused no symptoms. The patient did not face a similar episode of pain until a year later.

That year, the patient presented to the emergency room with rib, flank, and upper abdominal pain as well as fever and vomiting, she was given IV saline, ketorolac, and paracetamol to ease the pain. Her abdomen was examined by a surgeon who could not pinpoint where the problem was at the time. Later that night, she was sent to the intensive care unit (ICU) to start fentanyl infusion $1 \mathrm{mcg} / \mathrm{kg} / \mathrm{h}$ 
where the dose was increased per hour until $4 \mathrm{mcg} / \mathrm{kg} / \mathrm{h}$. The next day, the patient was shifted to the ward and was on regular doses of tramadol and paracetamol. As for antibiotics, piperacillin-tazobactam IV was administered. Despite regular administration of analgesics, the pain did not subside, diclofenac intramuscular injection was given which was still ineffective. After detailed laboratory investigations, ultrasound, CT, and MRI, an exploratory diagnostic laparoscopy was advised, later performed under general anesthesia.

Details of the laparoscopy: A three port laparoscopic appendectomy was performed where multiple omental abscesses were drained, colon-omental adhesiolysis (Figure 3a) was done, and a long gangrenous retrocecal subhepatic appendix was discovered (Figure 3c), as well as an appendicular abscess (Figure 3b-g). The gangrenous portion was sloughed, appendix dissected out and base stapled along cecal cuff (Figure 3e).

The patient was kept NPO, vitals, and drain output monitored (Figure $3 \mathrm{~h}$ ). The antibiotics were changed to meropenem and metronidazole to ensure full double anaerobic coverage. Fentanyl, tramadol, and paracetamol were given. Ondansetron was also prescribed for vomiting after surgery.

\section{Follow- up and outcomes}

Postoperatively, the patient was monitored in the ICU for $24 \mathrm{~h}$, the drain was removed, the drainage port checked regularly, and dressings changed. The patient's condition gradually improved and she was shifted to the ward where she complained of continuous shoulder tip pain and nausea which was managed conservatively. She started following a soft food diet 2 days' postoperatively. Her bowel movements were exaggerated and had dark stools for 2 weeks. At the time of discharge, all vital signs appeared normal, and the pain score was $1 / 10$. The patient was stable, afebrile, and ambulated. The patient was discharged home in stable condition. Cefuroxime $500 \mathrm{mg}$, metronidazole $400 \mathrm{mg}$, pantoprazole $40 \mathrm{mg}$, and paracetamol $1 \mathrm{~g}$ were prescribed on discharge.

A follow-up appointment was placed 1 month postoperatively where the patient underwent an ultrasound of the whole abdomen: The right ovarian cyst had decreased in size, all organs appeared normal, minimal ascites on the left side was also not visible as it was present when the patient was admitted, this concludes a normal ultrasound study.

There were no further complaints and the patient's condition was improving. The patient gave written consent for publication of this case report.
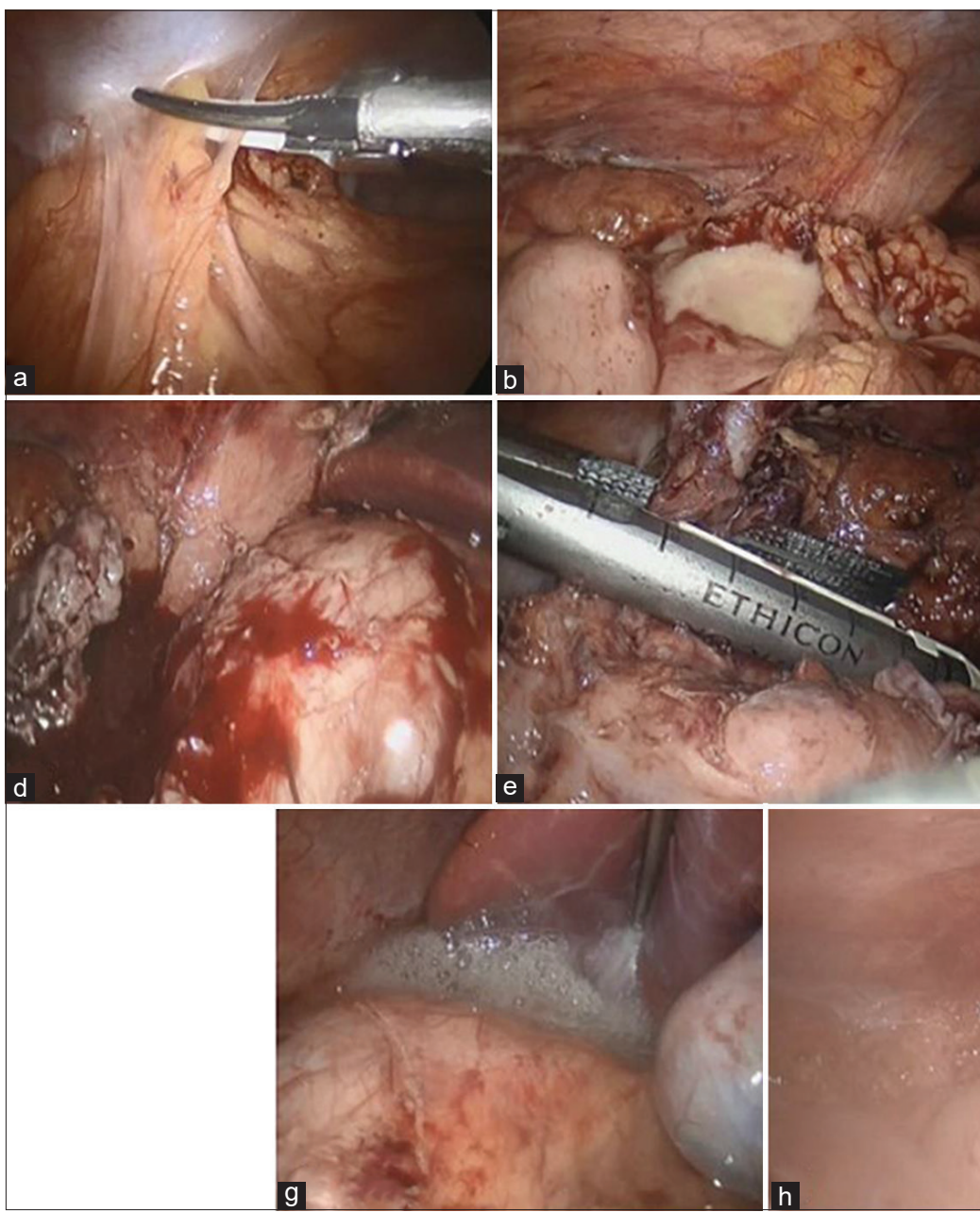
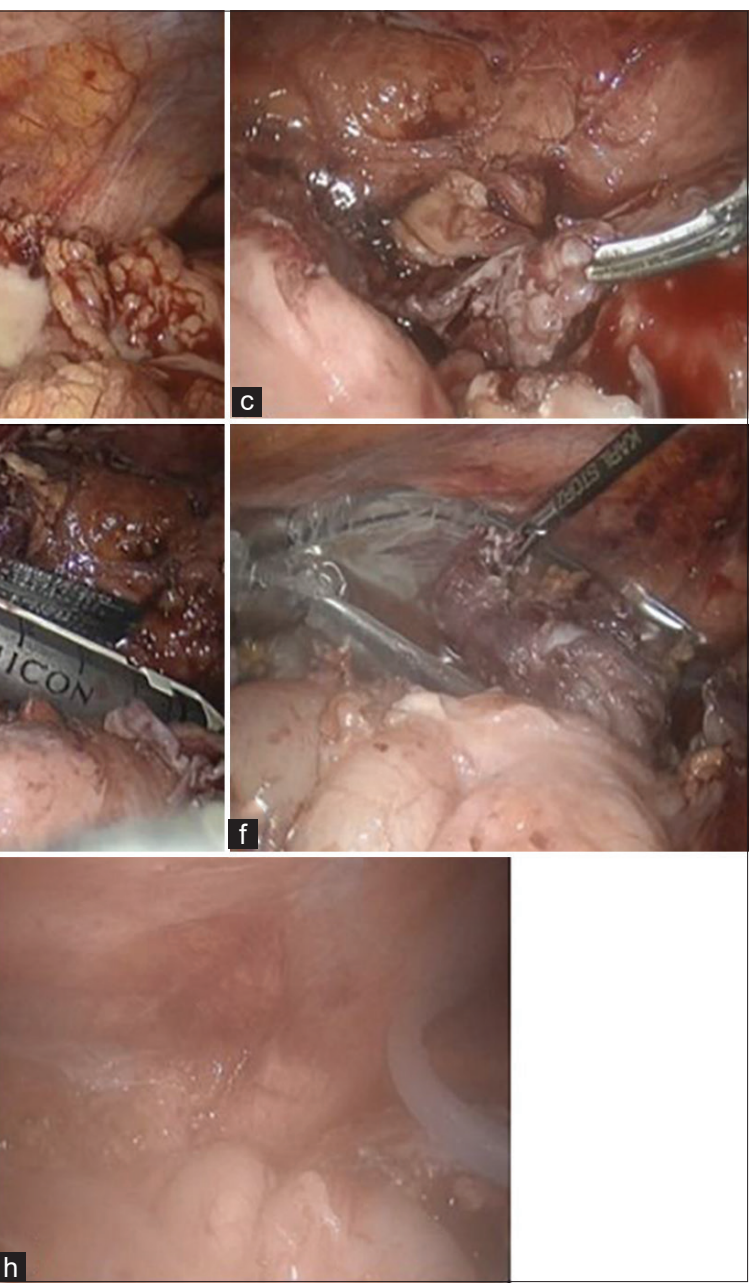

FIGURE 3. This 17 year old female presented with pyrexia, vomiting, nausea, unspecified abdominal pain and a palpable mass in the right lower quadrant of the abdomen. She had an explorative and diagnostic laparoscopic operation for removal of a long gangrenous ascending retrocecal and subhepatic gangrenous appendix. (a) Colo-omental adhesions found. (b) Appendicular abscess filling the subhepatic space. (c)(d) Tip of $11 \mathrm{~cm}$ long appendix present at the subhepatic space. (e) Staple division of sloughed gangrenous appendiceal base. (f) Appendectomy performed. Bagging of the appendix done. (g) Lavage of subhepatic space. (h) Placement of drain in the right upper abdominal quadrant. 


\section{DISCUSSION}

Despite the high prevalence of acute appendicitis, variations in location of the appendix and cecum during development make this straightforward disease, challenging to diagnose (7). Examination findings as well as symptoms differ with different appendiceal locations, this should be considered by surgeons and physicians when evaluating a case of abdominal, flank, or back pain. The following are similar scenarios to the one in this article:

A 14-year-old female dancer presented with severe back pain. The pain was severe enough to cause her to walk with a limp. One week before presentation, she experienced the onset of aching pain on both sides of the pelvis that was exacerbated with movement. She did not experience any abdominal pain, fever, nausea, or vomiting. On examination, there was tenderness of the lumbar paraspinal muscles bilaterally, most severe near the $5^{\text {th }}$ lumbar spine. Her abdomen was soft, non-tender, and non-distended. An MRI of the lumbar spine was done due to a clinical suspicion of having spondylosis, however, the scan showed no sign of injury to the vertebrae or spinal cord. Instead, an inflamed retrocecal and extraperitoneal appendix coursing along the psoas muscle measuring $9 \mathrm{~mm}$ with surrounding free fluid was noted. She underwent a laparoscopic appendectomy that confirmed this diagnosis (8).

A female athlete, 23 years of age, presented with right-sided lower back pain. She has no history of nausea, vomiting, fever, anorexia, or abdominal pain which are symptoms consistent with appendicitis. Two weeks of treatment with nonsteroidal anti-inflammatory were unsuccessful, as well as 6 weeks of symptomatic treatment for renal stones. Nephrolithiasis was suspected so she underwent a CT scan revealing a retrocecal appendix with wall thickening and fat stranding surrounding the appendix concluding to the diagnosis of appendicitis (9).

In another example, a 26-year-old female was rushed to the emergency department with pain in the right upper quadrant of 2 days duration. Rebound tenderness and tenderness were elicited in that quadrant. She also experienced nausea and anorexia since the pain started. The right upper quadrant pain can rule out the diagnosis of appendicitis and mostly suggests cholecystitis, gastritis, duodenal ulcer, and other liver or gallbladder pathologies, which lead to misdiagnosis and further complications if left untreated. On CT examination, retrocecal appendix was adherent to the liver capsule as well as retroperitoneum. The tip of the appendix was also phlegmonous and joined through retroperitoneum to the liver capsule. A pararenal abscess was also observed which suggests the spread of infection in cases of retrocecal appendicitis through the right paracolic gutter reaching the right subhepatic area (10).

According to recent guidelines on the diagnostic approach of appendicitis, clinical scores (i.e.: Alvarado, AAS, and AIR) should be used only to exclude the possibility of having appendicitis and not as a definitive diagnostic tool. Even though the Alvarado score is considered highly sensitive for the diagnosis of acute appendicitis, it is insufficient in specificity, is not able to differentiate complicated from uncomplicated acute appendicitis in the elderly, and seems less sensitive in HIV-positive patients (11). Other clinical scoring systems such as AAS and AIR are usually implemented along with Alvarado reducing the need of imaging studies in both low- and intermediate-risk groups. Among the clinical scores available, the AIR and AAS scores seem to have the highest specificity as it reduced the overall need for imaging and radiation exposure, as well as the number of negative appendectomy operations done (12). In case of an inconclusive ultrasound study, the use of contrast-enhanced low-dose CT scan is preferred over contrast-enhanced standard dose CT scan for young adults, having the advantage of lower radiation exposure, without changing diagnostic accuracy (3).

To improve diagnostic sensitivity and specificity, it is strongly recommended to combine the use of clinical scores along with POCUS findings. If you suspect appendicitis based on clinical examination of the patient, the use of POCUS as a first-line diagnostic approach has shown to be accurate in young adults (3).

\section{Patients ALVARADO score: 7 \\ 2. Patients AIR: 6 \\ 3. Patients AAS: 11 (Table 6).}

According to the clinical scoring systems used to identify the possibility of having appendicitis $(13,14)$, our patient lies in the intermediate risk group for the most part. The only drawback to these scores when calculating it in the case of our patient is that the site of pain is atypical and therefore not added into the total score.

The 2020 update of the WSES Jerusalem guidelines mentioned that patients that lie in the intermediate risk group, should undergo an ultrasound scan to identify the presence or absence of appendicitis, given that it is present, the decision to undergo surgery or going for non-operative management depends on the patient's age. If $<40$ years old, and there is no evidence of an appendicolith on ultrasound scan, there are two routes to choose from. First, to directly undergo an appendectomy surgery. Second, is to undergo a trial of non-operative management with antibiotics, after which the patient is reexamined in $6-8 \mathrm{~h}$, and the score is reevaluated. If symptoms persist, laparoscopic surgery is indicated. If not, the patient is discharged (3).

Any case of fever, nausea, vomiting, leukocytosis, and high CRP would ring a bell to any physician that there is presence of an acute inflammation and infection somewhere in the body. Other specific signs and symptoms discovered by the doctor, or experienced by the patient, would guide us to a diagnosis. Symptoms such as a specific site and character of pain can aid in directing the diagnostic approach in the right way. In atypical cases of appendicitis where there is no clear indication of its presence, a high clinical suspicion of appendicitis is needed to lead the surgeon to calculate the scores and follow the guidelines on diagnostic approach of appendicitis. The site of pain is considered as a determining factor in a typical case of appendicitis, yet in this case, this factor is the most misleading. 
TABLE 6. Calculation of scores using the Alvarado, the AIR, and the AAS scoring systems

\begin{tabular}{|c|c|c|c|}
\hline Diagnosis & Alvarado & AIR & AAS \\
\hline Vomiting & & 1 & \\
\hline Nausea or vomiting & 1 & & \\
\hline Anorexia & 1 & & \\
\hline Pain in RLQ & 2 & 1 & 2 \\
\hline Migration of pain to the RLQ & 1 & & 2 \\
\hline RLQ tenderness & & & $\begin{array}{l}\text { Women aged 16-49: } 1 \\
\text { All other patients: } 3\end{array}$ \\
\hline Guarding & & & $\begin{array}{l}\text { Mild: } 2 \\
\text { Moderate: } 4 \\
\text { Severe: } 4\end{array}$ \\
\hline $\begin{array}{l}\text { Rebound tenderness or muscular } \\
\text { defense: }\end{array}$ & 1 & $\begin{array}{l}\text { Light: } 1 \\
\text { Medium: } 2 \\
\text { Strong: } 3\end{array}$ & \\
\hline Body temperature & $>37.5^{\circ} \mathrm{C}: 1$ & $>38.5^{\circ} \mathrm{C}: 1$ & \\
\hline Leukocytosis shift & 1 & & \\
\hline Polymorphonuclear leukocytes & & $\begin{array}{l}70-84 \%: 1 \\
\geq 85 \%: 2\end{array}$ & \\
\hline Neutrophils (\%) & & & $\begin{array}{l}>62-<75: 2 \\
>75-<83: 3 \\
\quad>83: 4\end{array}$ \\
\hline WBC (LEUKOCYTE) count & $>10.0 \times 10^{9} /:: 2$ & $10.0-14.9 \times 10^{9} /: 1$ & $\begin{array}{l}>7.2-<10.9: 1 \\
>10.9-<14.0: 2\end{array}$ \\
\hline & & $\geq 15.0 \times 10^{9} / \mathrm{l}: 2$ & $>14.0: 3$ \\
\hline CRP concentration & & $\begin{array}{c}10-49 \mathrm{~g} / \mathrm{l}: 1 \\
\geq 50 \mathrm{~g} / \mathrm{l}: 2\end{array}$ & $\begin{aligned} \mathrm{CRP} \text { in } \mathrm{mg} / \mathrm{l} \text { If symptoms }<24 \mathrm{~h} \\
>4-<11: 2 \\
>11-<25: 3 \\
>25-<83: 5 \\
>83: 1 \\
\text { CRP in } \mathrm{mg} / \mathrm{l} \text { If symptoms }>24 \mathrm{hr} \\
>12-<53: 2 \\
>53-<152: 2 \\
>152: 1\end{aligned}$ \\
\hline Total score & 10 & 12 & \\
\hline Interpretation of score & $\begin{array}{l}\text { 0-4: Not likely appendicitis } \\
\text { 5-6: Equivocal } \\
\text { 7-8: Probably appendicitis } \\
\text { 9-10: Highly likely }\end{array}$ & $\begin{array}{l}\text { 0-4: Low probability } \\
\text { 5-8: Intermediate group } \\
\text { 9-12: High probability }\end{array}$ & $\begin{array}{l}\leq 10 \text { : low risk } \\
\text { 11-15: intermediate risk } \\
\geq 16 \text { : high risk }\end{array}$ \\
\hline
\end{tabular}

\section{CONCLUSION}

1. Each patient should have their personal tailored diagnostic approach and treatment

2. Completely dependence on clinical scores alone will result in delayed and missed diagnoses. Combine clinical scores with radiological imaging techniques to achieve a definitive diagnosis

3. Clinicians must be conversant with the latest WSES guidelines regarding the management of acute appendicitis

4. Dependence must not be placed on clear cut textbook presentations, considering the various differentials possible.

\section{PATIENT'S PERSPECTIVE}

"Going through this experience was a huge wake up call for me. I was always active, healthy and had no medical issues whatsoever. Because of that, I did not look ill at all despite the continuous pain, fever and vomiting. No doctor believed that I was in pain because I looked completely normal. I was misdiagnosed multiple times with ovarian cyst, colitis, and UTI. The second time I got admitted, I was misdiagnosed again but did not settle for that diagnosis, I knew something else was wrong. No scans and no laboratory investigations assisted with a clear diagnosis. Frankly, as the days passed with continuous pain and no diagnosis, I was slowly accepting everything going on and was ready to live with it. I knew something was seriously wrong and I knew my condition was lethal if not treated. Being in the medical field, I knew what sepsis was and how it ends up if not managed rapidly, and that's all I heard from the doctors during my hospital stay, this made me give up and just accept whatever I had. This experience made me eager to know the reasons behind everything in medicine. This experience taught me to think outside the box, and to not always go by the books. Getting as much practice as you can as a physician is important, looking out for real life scenarios and studying them. Always be thankful for the life you're given, you never know when your time will come, no matter how young you are."

\section{CONFLICT OF INTERESTS}

Authors declare no conflict of interest. 


\section{REFERENCES}

1. Craig S. Appendicitis: Practice Essentials, Background, Anatomy; 2020. Available from: https://www.emedicine.medscape.com/article/773895-overview. [Last accessed on 2020 Aug 12].

2. Ohle R, O'Reilly F, O'Brien K, Fahey T, Dimitrov B. The Alvarado score for predicting acute appendicitis: A systematic review. BMC Med 2011;9(1):139. https://doi.org/10.1186/1741-7015-9-139

3. Di Saverio S, Podda M, De Simone B, Ceresoli M, Augustin G, Gori A, et al. Diagnosis and treatment of acute appendicitis: 2020 update of the WSES Jerusalem guidelines. World J Emerg Surg 2020;15(1):27.

4. Humes D, Simpson J. Acute appendicitis. BMJ 2006;333:530-4.

5. Thompson JP, Selvaraj D, Nicola R. Mimickers of acute appendicitis. J Am Osteopath Coll Radiol 2014;3(4):10-21.

6. Stern E, Sugumar K, Journey J. Peptic Ulcer Perforated; 2020. Available from: https:// www.statpearls.com/articlelibrary/viewarticle/26938. [Last accessed on 2021 Jan 08].

7. Nayak SB, George BM, Mishra S, Surendran S, Shetty P, Shetty SD. Sessile ileum, subhepatic cecum, and uncinate appendix that might lead to a diagnostic dilemma. Anat Cell Biol 2013;46(4):296-8.

https://doi.org/10.5115/acb.2013.46.4.296.

8. Onwuka E, Drews J, Prasad V, Nwomeh B. A rare presentation of a common entity: Chronic appendicitis in a patient with back pain. J Pediatr Surg Case Rep 2017;18:4-6. https://doi.org/10.1016/j.epsc.2017.01.002.

9. Drezner JA, Harmon KG. Chronic appendicitis presenting as low back pain in a recreational athlete. Clin J Sport Med 2002;12:184-6.

https://doi.org/10.1097/00042752-200205000-00008.

10. Borekci H, Karacabey S, Sipahi M, Ozdemir Z, Erkoc M. A rare case: Retrocecal appendicitis adherent to the liver capsule. Turk J Surg 2017;33(3):227-9. https://doi.org/10.5152/ucd.2015.2963.

11. Gope D, Dnayanmote A, Thakkar S, Tulsian A, Kutty S, Ranka M, et al. Comparison between AIR score and Alvarado score in cases of non-perforated and perforated acute appendicitis. Int Surg J 2019;6(4):1108.

https://doi.org/10.18203/2349-2902.isj20191028.

12. Abuomar M, Elshakhs S, Abdelsamie M, Fareed A. Reliability of the adult appendicitis score in diagnosing acute appendicitis. Menoufia Med J 2019;32(2):544. https://doi.org/10.4103/mmj.mmj_914_17.

13. Sammalkorpi $H$, Mentula $P$, Savolainen $H$, Leppäniemi $A$. The introduction of adult appendicitis score reduced negative appendectomy rate. Scand J Surg 2017;106(3):196-201.

https://doi.org/10.1177/1457496916683099.

14. Andersson R. Evaluation of the appendicitis inflammatory response score for patients with acute appendicitis. World J Surg 2012;36(7):1546-7

https://doi.org/10.1007/s00268-012-1552-x. 